\title{
The Impact of Prior Victimization and Socio-Economic Status on People's Crime-Reporting Behavior
}

\author{
Avdi S. Avdija ${ }^{1, *}$, Dennis M. Giever ${ }^{2}$ \\ ${ }^{1}$ Department of Criminology and Criminal Justice, Indiana State University, Terre Haute, IN, USA \\ ${ }^{2}$ Department of Criminology, Indiana University of Pennsylvania, Indiana, PA, USA
}

\begin{abstract}
The purpose of this study is to determine whether or not prior victimization, along with socio-economic status affect people's willingness to report crimes to authorities. This study is limited to addressing the effect of prior victimization on willingness to report crimes by 1 ) the type of victimization (i.e., being a victim of property crimes or a victim of crimes against persons), 2) being a victim of a crime, regardless of the type of crime versus not being a victim, and 3) the difference in crime-reporting variation between the two. The findings of this research study are based on the analyses of the data that have been collected through a self-admin istered survey questionnaire distributed to 531 undergraduate university students. Overall, the findings that emerged from this study suggest that prior victimization cannot be considered a good predictor of crime-reporting behavior.
\end{abstract}

Keywords Crime-Reporting Behavior, Victimization, Socio-Economic Status, Property Crimes, Crimes Against Persons

\section{Introduction}

Crime-reporting behavior is generally considered a form of willingness to report crimes to authorities. The review of the existing literature on crime-reporting behavior shows that people's willingness to report crime to the police is influenced by a host of interrelated factors. Some of those factors have a direct effect on crime-reporting behavior; some of them have a meandering effect through negative or positive attitudes toward the police on crime-reporting behavior. Most prior studies in this area have studied crime-reporting behavior in part. Yet, most researchers have been focused on one type of crime or on factors that have been vaguely conceptualized.

The current study includes prior victimization as a primary variable that influences one's willingness to report crime to the police. After all, there are a considerable number of studies that show prior victimization is an important factor that affects crime-reporting behavior[1-10]. Prior victimization in this study, as a variable, has two dimensions, victimization by crime (i.e., crimes against property and crimes against persons) and victimization by the police (e.g., police misconduct).

In this study, victimization by the police, however, will only be considered in reference to the review of existing literature on victimization.

* Corresponding author:

avdi.avdija@indstate.edu (Avdi S. Avdija)

Published online at http://journal.sapub.org/ijap

Copyright (C) 2012 Scientific \& Academic Publishing. All Rights Reserved

\subsection{For ms of Victi mization}

Victimization takes many different forms, including domestic abuse by individuals close to the victim, other non-domestic victimization, frequency of victimization events, time of occurrence, location of occurrence (e.g., public location vs. private location), different types of victimization (e.g., crimes against property vs. crimes against persons), and different degrees of severity of victimization (e.g., from murder, rape, repeat-assaults, to property loss). Each one of these forms of victimization differs in terms of propensity to report victimization events to the police, and each form of victimization may be explained by different sets of correlates [see, 1-4,6,9,11].

\subsection{The Effect of Victimization Experiences on Crime-Repor ting Behavior}

Xie et al. researched the relationship between factors that affect crime-reporting behavior for individuals who have been victimized by crime. The major assumptions in their study were that crime-report ing behavior will be affected by the victim's prior experience with the police, by whether or not an arrest was made by the police in an effort to investigate the crime that has affected the victim, and by the police response to an individual's own prior victimization rather than victimization of another household member[8]. To test these hypotheses, the researchers analyzed longitudinal data borrowed from the NCVS (National Crime Victimization Survey) of 2002. In their study, Xei et al. found that the greater the police efforts following the most recent victimization of an individual, the greater the 
likelihood that that individual will report subsequent victimization events to the police. Furthermore, consistent with Hickman and Simpson's[12] and Holmberg's[13] research findings, Xei et al.'s research shows that a positive police response to prior victimization (i.e., if the offender who committed the crime against the victim was arrested) encouraged victims to report subs equent crimes to the police. Regarding vicarious reporting of crimes ${ }^{1}$ to the police, Xei et al.'s research shows that victimization of, for example, another household member did not have an effect on an individual's crime-reporting behavior ${ }^{2}$. This study points out that prior victimization is strongly associated with crime-reporting behavior. Therefore, those who have been previously victimized by a crime are more likely to report subsequent crimes to the police [8]. Moreover, the findings of an earlier study conducted by Conaway and Lohr also confirm that crime-reporting behavior is strongly associated with one's prior victimization status. Conaway and Lohr's analysis of factors as sociated with reporting vio lent crimes to the police show that people who have been previously victimized, regardless of the type of victimization, are more likely to report subsequent victimization events to the police[5].

In general, research shows that as the frequency of victimization events increases, reporting victimization events to the police also increases. This hypothes is has been empirically supported by the research findings of Unnever and Cornell's study[14]. According to Unnever and Cornell, who examined factors that influence students' decisions to report being bullied to school officials, victims who reported bullying to school officials increased as the persistency of victimization increased. In other words, the findings of this study suggest that the higher the repetition of victimization is, the higher the reporting rates will be[14,15]. Research findings of Williams and Cornell also show that there is a positive influence on students' willingness to seek help for a threat of violence when they have been previously victimized by crime[16]. This tells us that there is a reason to believe that an increased number of victimization events is positively correlated with willingness to report subsequent victimization events to the police. However, this conclusion is not universally supported by all prior research. Zhang, Messner, and Liu, for example, found that there is a negative effect of prior victimization on reporting subsequent victimization events. This study shows that individuals who

\footnotetext{
1 Vicarious reporting of crimes to the police refers to actions taken by other individuals, other than the victim or the witness of a specific crime. For example, if someone witnesses a crime but is not willing to report it to the police, rather informs a friend or a family member of that crime occurrence, and now the second person (e.g., friend or family member) reports it to the police. This form of reporting is referred to as "vicarious reporting."

${ }^{2}$ In this study, crime-reporting behavior refers to people's willingness to report (future) crimes to the authorities. In other words, we assessed the reporting behavior and a specific number of factors (e.g., prior victimization and SES) that influence this behavior rather than the actual number of crimes that one has reported to the police in the past. The phrase "crime-reporting behavior" in this study is also used in reference to the existing literature, again in reference to people's willingness to report crimes to the police or other authorities.
}

have been previously victimized by crimes were less likely to report subsequent crimes to the police. The authors explained that following a victimization event, victims of crime may submerge into an increased isolation from the mainstream society, creating a defensive shield, which is perceived by the victims to serve as a mechanism against future victimizations [11]. Nonetheless, Zhang et al. maintain that crime-reporting behavior is explained by incident-specific correlates, individual-specific correlates, and environmental-specific correlates.

\subsection{Socio-Economic Status}

Prior research shows that people who live in economically disadvantaged neighborhoods are less willing to cooperate with the police. Lack of cooperation, in this context, is manifested in the form of unwillingness to report witnessed crimes or victimization events to the police[17-21]. Thus, socio-economic status at the neighborhood level as well as at the individual level affects crime-reporting behavior. This effect is observed in many levels. Caracach[22] argued that people who find themselves in difficult financial situations (e.g., unemployed) are less likely to report crimes to the police[see also 23]. In addition to its effect on crime-reporting behavior, socio-economic status affects attitudes toward the police too, which in turn, increases the total effect that socio-economic status has on crime-reporting behavior[22]. Johnson in his study indicates that attitudes toward the police were the most negative among persons with income below \$20,000, the unemployed, and non-homeowners. Moreover, economically disadvantaged neighborhoods tend to have a higher level of crime co mpared to more economically developed neighborhoods[24]. In high-crime areas the police then are more likely to exercise coercive means, including police use of excessive force, which negatively affects both residents' attitudes toward the police and their crime-reporting behavior (17-19, 25-29].

At the individual level, research shows that lower-income pers ons, overall, are slightly less like ly to report crimes to the police compared to high-income persons. However, this behavior varies by the type of crimes, i.e., property crime or violent crime. Goudriaan's study, for example, shows that property crime, especially, is more likely to be reported to the police by high-income families compared to low-income families[3]. Skogan's study also confirms that high-income families are more likely to report property crime[30]. According to Skogan, families of high-income reported about $14 \%$ more property crimes to the police compared to low-income families[30]. This tells us that, in most cases, crime-reporting behavior that is based on socio-economic status is explained by its consequences. That is, reporting certain property crimes to the police is done with intent of recovery, for insurance purposes, or in some cases, as an expression of anger[3,4,31]. This, however, should not be confused with crime-reporting behavior that is based on the seriousness of crime. Vio lent crimes, on the other hand, are more likely to be reported by lower-income persons. 
Lower-inco me victims of rape, for example, are mo re likely to report victimization events to the police than higher-income victims[3]. Skogan's study shows that low-income families report about $19 \%$ more violent crimes than high-income families (Skogan, [1,30,32]. Perhaps low-income families are more often victimized by violent crimes than high-income families. Research confirms this assumption. Statistics show that low-income persons have higher victimization rates for violent crimes $(47 \%$ for those who make $\$ 7,500$ or less annually) than high-income persons $(18 \%$ for those who make $\$ 75,000$ or more annually)[33]. Conversely, high-income families are more often victims of property crime, simply because they possess more property that can be targeted by potential offenders [34]. Generally, research shows that the percentage of reported crimes against persons declines as the household income increases $[35,32,11]$. And the percentage of reported property crimes increases as the household income increases. Needless to say, these crime-reporting statistics vary from city to city.

Arguably, crime-reporting behavior is affected by one's socio-economic status. Yet, socio-economic status has an impact on one's attitudes toward the police, which in turn, affect one's willingness to report crimes to the police. In short, research shows that the effect of socio-economic status on attitudes toward the police is manifested in lower crime-reporting behavior. And the effect of socio-economic status on crime-reporting behavior varies by the type of crime (e.g., property crime vs, vio lent crime).

\subsection{Serious ness of Crime}

The decision whether or not to report a crime to the police, to a large extent, is affected by the severity or the consequences of the criminal event. Thus, individual perception about the seriousness of crime plays an important role in crime-reporting behavior $[22,36]$. Skogan argued that crime-reporting behavior is a form of individual evaluation of the events in terms of cost-benefit rational[34]. Thus, according to Skogan, crimes that tend to produce some form of personal gain (e.g., property crimes) are more likely to be reported to the police[34,3,10]. ${ }^{3}$ For example, those who have insured property, and that the property will be fully compensated by the insurance companies, are more likely to report property theft to the police (84\%) compared to those who do not have property insurance (51\%)[37]. However, the seriousness of crime does not stop at the value of property. In fact, it is much broader than property crime; it includes crimes against persons as well. Research shows that the severity of crime becomes a stronger determinant of crime-reporting behavior when including violent crimes (e.g., victim inju ries, repeat victimization events, etc.)[38-41,35]. Tanton and Jones's study shows that victims of serious crimes have a higher propensity to report crimes to the police

\footnotetext{
${ }^{3}$ See discussion in the previous section (under Socio-Economic Status section) for a more detailed account of the influence of SES on crime-reporting behavior.
}

than victims of less serious crimes. Victims who had experienced injuries during an assault, for example, were associated with higher reporting of the event to the police[10,42]. According to the Bureau of Justice Statistics, $56 \%$ of victimizations that resulted in injuries were reported to the police compared to $40 \%$ of victimization events that did not involve injuries [35]. Additionally, crime-reporting is further influenced by the degree of the severity of injury (i.e., severe injuries are more likely to get reported than light injuries). The Bureau of Justice Statistics's study shows that $70 \%$ of victims who received medical treatment for their injuries reported the event to the police compared to $46 \%$ of victims who did not receive medical treatment for their injuries[35].

The impetus behind crime-reporting behavior for violent crimes is the victims' perception that they will have a greater benefit frompolice involvement. That is, if victims of violent crimes report their victimization events to the police, it means that they can put a stop to their victimization[43]. This argument is consistent with Skogan's[30,34] cost-benefit rational; a form of rational choice perspective in which victims of crime perceive crime-reporting as beneficial[44].

Furthermore, Watkins argued that the severity of crime differs by age[43]. That is, juveniles are more likely to witness or become victimized by less severe crime. Watkins's findings indicate that juveniles are less willing to report crime to the police, not entirely because of their age, but because of the seriousness of the crime[43]. This translates that juveniles are more likely to engage in less serious crimes; thus, their victimization is not as severe as that of adults[33,30]. Additionally, people are more likely to report crimes when such events result in injuries and great property loss. For juveniles, property loss, in most cases, is not applicable[see 40, 45,46, for reviews].

\subsection{The Present Study}

In this study, we tested three research hypotheses about the influence of prior victimization on crime-reporting behavior. Research shows that victimization experiences have a positive influence on crime-reporting behavior. In this context, empirical evidence suggests that those who have been previously victimized by crime are mo re likely to report crimes to the police $[8,47,48]$. Of the two types of victimizations (i.e., crimes against property vs. crimes against persons), as discussed above, research shows that victims of property crimes are more likely to report crimes to the police in general. Additionally, research also shows that as the severity of crimes and frequency of their occurrence increases, so does the like lihood of reporting those crimes to the police, especially crimes that involve some kind of weapon $[5,8,10,13,22,36,37,45,46$ see also $14,16,35]$. However, what makes the inclusion of prior victimization relevant to this study is that there is a number of studies that do not support the above conclusions[see $11,34,49$,]. Thus, to clarify this issue, further testing is needed. To address the influence of prior victimization on crime-reporting behavior, the following research hypotheses were tested: 
Ha (1): Individuals who have been previously victimized by crime (regardless of the type of crime: e.g., property crime or crimes against persons) are more likely to report victimization events or witnessed crimes to the police compared to those who have not been previously victimized by crime.

Ha (2): Individuals who have been victims of property crimes are more likely to report victimization events or witnessed crimes to the police compared to those who have not been victims of property crimes.

Ha (3): Controlling for socio-economic status, individuals who have been victims of crimes against persons are less likely to report victimization events or witnessed crimes to the police compared to individuals who have not been victims of crimes against persons.

\section{Methods}

\subsection{Participants}

The data for this research study were collected in 2009 as part of a larger study on crime-reporting behavior. A 111-item survey questionnaire was distributed to a sample of 531 undergraduate university students (248 males and 283 females) in six colleges, who ranged in age from 18 to 52 years $(M=22, S D=4.5)$. In terms of race/ethnicity, the majority of the participants identified themselves as Whites (72.3\%), followed by African Americans (16.1\%), Asians $(3.8 \%)$, Hispanic/Latinos $(1.3 \%)$, and others $(6.5 \%)$. To draw the sample, we adopted a two-stage cluster sampling procedure, stratified by colleges. That is, we drew six sub-samples, one from each college, assuring an equal representation of all undergraduate university students in the final sample. The number of participants in each sub-sample was based on the percentage of students enrolled in each of the six colleges in a large public university in Pennsylvania. Since in this study we test three distinctive hypotheses, the research results should be viewed and interpreted within the confines of the scope of this study.

\section{Measures}

\subsection{Dependent Variables}

The dependent variable in this study is people's willingness to report crimes to the police. To measure this crime-reporting behavior, we used three separate composite measures with a total of 24 mini-scenarios/items (see Appendix A). The respondents were asked to read each response and, based on their personal perception, they were asked to mark their answers on a five-point Likert-scale (strongly disagree $=1$, disagree $=2$, neutral $=3$, agree $=4$, and strongly agree $=5$ ). In terms of reporting behavior by the type of crimes, these scales were designed to measure reporting of crimes against persons and reporting of crimes against property. Reporting of property crimes was measured using a 3-item Likert-scale with 1 to 5 response category $(1=$ strongly disagree to $5=$ strongly agree). By the degree of the severity of crimes, these three scales measured the reporting of crimes from the least severe (e.g., s moking marijuana, selling illicit drugs, painting graffiti, etc.), medium-level crimes (e.g., physical threats, future terroristic threats, etc), and serious crimes (e.g., kidnapping, rape, murder, etc.), The pool of 24 crime-reporting items was subjected to factor analys is using SPSS version 19.0 (Statistical Package for Social Science). Initially, the factorability of the 24 crime-reporting items was examined. To determine the factorability of these items, we used two criteria, namely the Keiser-Meyer-Oklin Test and the Bartlett's Test of Sphericity. The Kaiser-Meyer-Oklin value, which is a measure of the sampling adequacy, was .931, a value that greatly exceeded the minimum recommended value of .60[see 50-52]. The Bartlett's Test of Sphericity[53] for this pool of crime-reporting items also reached the statistical significance of $\mathrm{p}<.000$, which tells us that the analyses supported the elements that contributed to the results of the correlation matrix[see 54,55]. In other words, the relationships between items in the scale were statistically significant.

Furthermore, the initial results of the factor analysis that was conducted on the 24 crime-reporting items using the maximum likelihood extraction with the varimax rotation indicated that there were four factors with eigenvalues exceeding 1.0 , explaining $43.83 \%, 14.43 \%, 7.33 \%$, and $4.53 \%$ of the variance in crime-reporting behavior. After inspecting the scree plot, a three-factor solution was deemed suitable for further investigation. Thus, a second factor analysis with a forced extraction, limiting the number of extracted factors to three, was performed. The first factor, Factor 1, was labeled "crime-reporting 3," the second factor, Factor 2, was labeled "crime-reporting 1," and the third factor, Factor 3, was labeled "crime-reporting 2." In this context, the factor analysis was determinant in the formation of three crime-reporting scales in this study. The items that were grouped in Factor 1 measured the reporting of serious crimes (e.g., kidnapping, rape, murder, etc.), items that were grouped in Factor 2 measured the reporting of less serious crimes (e.g., smoking marijuana, selling illicit drugs, painting graffiti, etc.), and items that were grouped in Factor 3 measured the reporting of medium-level crimes (e.g., physical threats, future terroristic threats, etc). The ma in idea here was to extract a minimum number of factors that can explain the maximum amount of variance in the crime-reporting behavior.

The internal consistency coefficients computed for each crime-reporting scale was adequate, .89, 87, and .94, respectively, indicating that these measures have excellent reliability for research purposes. The results of scree test for each crime-reporting scale, which are based on principal component analysis, suggest that all three crime-reporting scales are unidimensional.

\subsection{Independent Variables}


The goal of this analysis was to test the effect of prior victimization (e.g., victimization of crimes against persons and crimes against property) and socio-economic status on crime-reporting behavior. The variables that measured prior victimization were binary (yes $=1, n o=0)$. Victimization for crimes against persons was measured by a 3 -item index. This included crimes such as robbery, aggravated assaults, and non-physical (verbal) threats. For robbery, the question asked, "Has someone taken something from you by force or threat of force?" For aggravated assaults, the question asked, "Has someone assaulted or attacked you personally? (An attack can be anything from being hit, grabbed, to being shot at or beaten)." For non-physical threats, the question asked, "Has someone verbally threatened you in any way?" Victimization for crimes against property, on the other hand, was measured by a 4-item index. This included burglary, vandalism, grand theft, and patty theft. Each variable had a binary response category (yes $=1, n o=0)$. For burglary, the question asked, "Has your house or apartment been broken into?" For vandalis $\mathrm{m}$, the question asked, "Has your car been broken into or vandalized?" For grand theft, the question asked, "Has your car been stolen?" And for petty theft, the question asked, "Has anyone tried to steal or stole anything (other than your car) that belongs to you?" Socio-economic status was measured on a 5-point scale (poor $=1$, lower middle-class $=2$, middle-class $=3$, upper middle-class $=4$, and rich $=5$ ). Other relevant variables, including demographic variables (age, gender, and race/ethnicity), public interaction with the police variables, police behavior, attitudes toward the police, fear of criminal retaliation, and crime-reporting anonymity were control variables.

\subsection{Control Variables}

As noted, to effectively test three specific research hypotheses, using multiple linear regression analysis, this study controls a number of variables, including police behavior, attitudes toward the police, public interaction with the police, fear of criminal retaliation, and crime-reporting anonymity (the desire to rema in anonymous when calling the police to report a witnessed crime or victimization event). In this study, police behavior was measured by a 22 -item scale (strongly disagree $=1$, disagree $=2$, neutral $=3$, agree $=4$, and strongly agree $=5$ ). This scale was highly reliable with Cronbach's Alpha $=.92$. Attitudes toward the police were measured using a 30-item Likert scale (Cronbach's Alpha $=.94)$. Fear of criminal retaliation was measured by a one single item with 1 to 5 response category (refer to Table 3 for the list of variables). We measured crime-reporting anonymity using a 4-item Likert scale (Cronbach's Alpha $=.71)^{4}$. Additionally, we controlled for the effect of a number of demographic variables such as age, gender, and

\footnotetext{
4 Results from the factor analysis using the maximum likelihood extraction with the varimax rotation indicated that attitudes toward the police, police behavior, and crime-reporting anonymity were unidimensional constructs. Due to space limitations, factor analyses for these three scales are not presented in this paper.
}

race/ethnicity. Age was measured in years. Gender was a dichotomous variable ( male $\operatorname{coded}=1$, female coded $=0$ ). Race/ethnicity was also measured as a dichotomous variable, with whites being the base category. After the recoding procedure took place, we created three categories for race: Black $($ yes $=1$, no $=0)$, Asian $($ yes $=1$, no $=0)$, Other $($ yes $=$ 1 , no $=0$ ), with Whites selected as the base category.

In terms of interpreting the coefficients for the scales, a higher score on the police behavior scale, for instance, indicates the presence of police misconduct, and a lower score indicates the absence of police misconduct. A higher score on the crime-reporting anonymity scale indicates that respondents were concerned with their identity being revealed, whereas a lower score indicates the respondents were not concerned with anonymity when reporting crimes to the police. A higher score on attitudes toward the police scale indicates positive attitudes toward the police, whereas a lower score indicates disfavorable attitudes toward the police.

Among other control variables in this study was public interaction with the police. There were five variables that were used to measure public interaction with the police. This interaction was measured in terms of the quantity and quality of contacts with the police. The quality of contacts with the police refers to the types of contacts people had with the police, namely police-initiated and citizen-in itiated contacts. To measure police-initiated contacts, we used a 12-item list of possible mini-scenarios pertaining to police-initiated contacts. To measure citizen-initiated contacts with the police, we used a 9-item list of possible mini-scenarios pertaining to citizen-initiated contacts. Each item had a binary response category ( $Y e s=1, N o=0)$. In some instances, people may not have contacts with the police, but they still have an opinion about the police. Weitzer and Tuch, for example, contend that some people create their opinion about the police based on what they see on television[56,57]. To capture this influence, we used a one 4-point Likert item ranging fro 0 (never) to 4 (often) that asked respondents to indicate how often they heard or read about police misconduct on TV, radio, newspapers, internet, etc., a survey item that was borrowed from Weitzer and Tuch's study[56]. This single item was designed to measure the influence of media exposure on people's decisions whether or not to report witnessed crimes or victimization events to the police; a vicarious form of contact with the police.

\subsection{Social Desirability}

To determine whether or not the respondents have introduced personal bias in their answers to other inventories (scales), for validity purposes, a 12-item personal reaction inventory (scale) with binary response categories (Yes $=1$, $N o=0$ ) was used (see 58-60]. People have a tendency to over-report or under-report activities that are considered to be socially or cu lturally desirable or undesirable[61-63]. The concern with this effect is that the respondents who tend to respond in more socially desirable ways are more likely to indicate they will report crimes to the police when in fact the 
reality is otherwise. This 12-item scale has a Cronbach's Alpha of .66, which is considered a minimally acceptable level of reliability[62]. A higher correlation between social desirability scale and other scales indicates that the respondents have introduced some bias in their answers. Conversely, a lower correlation indicates that the respondents have answered truthfully. The correlation analys is shows that the effect of social desirability bias on respondents concerning the truthfulness of their responses was minimal $(r<.03)$, which adds to the validity and reliability of the research findings in this study.

\section{Results}

Hypothesis 1 predicted that individuals who have been previously victimized by crime, regardless of the type of crime (e.g., property crime or crimes against persons) are more likely to report victimization events or witnessed crimes to the police compared to those who have not been victimized by crime. In other words, prior victimization has a positive effect on crime-reporting behavior. To evaluate the effect of prior victimization on crime-reporting behavior, we used a one-factor between-groups analys is of variance. The analyses in Table 1 show that those who had been previously victimized by crime were slightly more likely to report less serious crimes $(\mathrm{M}=23.28, \mathrm{SD}=8.516, \mathrm{p}<.284)$ compared to those who have not been previously victimized by crime $(\mathrm{M}=22.34, \mathrm{SD}=8.739)$. Additionally, prior victimization had a positive effect on the reporting of med iu m-level crimes $(\mathrm{M}=22.52, \mathrm{SD}=5.632, \mathrm{p}<.533)$ and serious crimes $(\mathrm{M}=$ 43.42, $\mathrm{SD}=9.186, \mathrm{p}<.733)$. However, the mean differences in crime-reporting behavior for those victimized by crime and those not victimized by crime were statistically insignificant. Therefore, hypothes is 1 is rejected.

Hypothesis 2 predicted that individuals who have been victims of property crimes are more likely to report victimization events or witnessed crimes to the police compared to those who have not been victims of property crimes. This hypothes is has not been supported by the data in this study at either the bivariate level (Table 2) or the multivariate level (see Table 3). It is noteworthy that the data in this study suggest that being a vict im of property crime has a positive effect on the reporting of less serious crimes $[\mathrm{b}$ $=.016, \mathrm{~F}(1,529)=000, \mathrm{p}<.983]$ and the reporting of serious crimes $[\mathrm{b}=.186, \mathrm{~F}(1,529)=.057, \mathrm{p}<.811]$, but a negative effect on the reporting of medium-level crimes $[\mathrm{b}=$ $-.262, \mathrm{~F}(1,529)=.272, \mathrm{p}<.602]$. Regardless of the positive or negative directions of the relationship, hypothesis 2 is rejected since it failed to reach the specified statistical significance of $p$ (critical) $<.05$.

Table 1. One-Fact or ANOVA: Comparing Means forThose Who Have Been Victimized and Who Have Not Been Victimized for Both Property \& Crimes against Persons $(\mathrm{n}=531)$

\begin{tabular}{|c|c|c|c|c|}
\hline Variable & $\mathrm{n}$ & Mean & Std. Deviation & $\begin{array}{l}\text { Std. Error of } \\
\text { Mean }\end{array}$ \\
\hline \multicolumn{5}{|l|}{ Crime-Reporting } \\
\hline Victimized & 129 & 23.28 & 8.516 & 750 \\
\hline Not victimized & 402 & 22.34 & 8.739 & 436 \\
\hline Total & 531 & 22.65 & 8.686 & 377 \\
\hline \multicolumn{5}{|c|}{$\mathrm{Eta}^{2}=.002, \mathrm{~F}(1,529)=1.152$, Sig. $=.284$} \\
\hline \multicolumn{5}{|c|}{ Crime-Reporting 2} \\
\hline Victimized & 129 & 22.52 & 5.632 & 496 \\
\hline Not victimized & 402 & 22.16 & 5.774 & 288 \\
\hline Total & 531 & 22.24 & 5.737 & 249 \\
\hline \multicolumn{5}{|c|}{$\mathrm{Eta}^{2}=.001, \mathrm{~F}(1,529)=.390$, Sig. $=.533$} \\
\hline \multicolumn{5}{|c|}{ Crime-Reporting 3} \\
\hline Victimized & 129 & 43.42 & 9.186 & 809 \\
\hline Not vict imized & 402 & 43.11 & 8.769 & 437 \\
\hline Total & 531 & 43.19 & 8.864 & .385 \\
\hline
\end{tabular}

Note: Dependent Variables: Constant $(1)=$ Crime-reporting 1 (scale for measuring the reporting ofless serious crimes). Constant $(2)=$ Crime-reporting 2 (scale for measuring the reporting of medium-level crimes). Constant $(3)=$ Crime-reporting 3 (scale for measuring the reporting of serious crimes ).

Table 2. Bivariate Regression Analysis: Regressing Crime-Reporting Behavior on Prior Victimization forProperty Crimes) $(\mathrm{n}=531)$ 


\begin{tabular}{|c|c|c|c|c|}
\hline Independent & Unstandardized & & Standardized & \\
\hline Variables & Coefficients & Std. Error & Coefficients & $\mathrm{t}$ \\
\hline Constant (1) & 22.556 & .571 & --- & --- \\
\hline $\begin{array}{l}\text { Victim of Property } \\
\text { Crime }\end{array}$ & .016 & 761 & .001 & .021 \\
\hline \multicolumn{5}{|c|}{$\mathrm{R} 2=.000, \mathrm{~F}(1,529)=.000$} \\
\hline Constant (2) & .22 .392 & .377 & ---- & --- \\
\hline $\begin{array}{l}\text { Victim of Property } \\
\text { Crime }\end{array}$ & -.262 & .502 & -.023 & -.521 \\
\hline \multicolumn{5}{|c|}{$\mathrm{R} 2=.001, \mathrm{~F}(1,529)=.272$} \\
\hline Const ant (3) & .43 .082 & .582 & --- & --- \\
\hline $\begin{array}{l}\text { Victim of Property } \\
\text { Crime }\end{array}$ & .186 & .776 & .010 & .239 \\
\hline $\mathrm{R} 2=.000, \mathrm{~F}(1,529$ & & & & \\
\hline
\end{tabular}

Note: ***Significance at the .001 level. **Significance at the .01 level. *Significance at the .05 level. Dependent Variables: Constant $(1)=$ Crime-reporting 1 (scale for measuring the reporting of less serious crimes). Constant $(2)=$ Crime-reporting 2 (scale for measuring the reporting of medium-level crimes). Constant (3)= Crime-reporting 3 (scale for measuring the reporting of serious crimes).

Table 3. Multivariate Regression Analysis: Regressing Crime-Reporting Behavior on Independent Variables ( $\mathrm{n}=531)$

\begin{tabular}{|c|c|c|c|c|c|c|}
\hline \multirow{3}{*}{$\begin{array}{l}\text { Independent } \\
\text { Variables }\end{array}$} & \multirow{2}{*}{\multicolumn{2}{|c|}{$\begin{array}{c}\text { Crime-Report ing } 1 \\
\text { Model } 1\end{array}$}} & \multirow{2}{*}{\multicolumn{2}{|c|}{$\begin{array}{c}\text { Crime-Reporting } 2 \\
\text { Model } 2\end{array}$}} & \multirow{2}{*}{\multicolumn{2}{|c|}{$\begin{array}{c}\text { Crime-Reporting } 3 \\
\text { Model } 3\end{array}$}} \\
\hline & & & & & & \\
\hline & $\mathrm{b}$ & $\mathrm{B}$ & $\mathrm{b}$ & $\mathrm{B}$ & $\mathrm{b}$ & $\mathrm{B}$ \\
\hline Constant & $10.040 * * *$ & --- & $17.846^{* * *}$ & --- & $40.824 * * *$ & --- \\
\hline Age & .485 & .055 & .392 & .068 & $.898^{* *}$ & .100 \\
\hline Gender (Male) & $-2.328^{* * *}$ & -.134 & $-2.122 * * *$ & -.185 & $-1.505^{*}$ & -.085 \\
\hline Asian & $-4.821 * * *$ & -.106 & $-5.294 * * *$ & -.176 & $-9.962 * * *$ & -.214 \\
\hline Black & $-.848 * *$ & -.036 & -.255 & -.016 & $3.751 * * *$ & -.155 \\
\hline Other Race & -.315 & -.010 & $-1.757^{*}$ & -.083 & $-4.023^{* *}$ & -.123 \\
\hline SES & -.487 & -.053 & .215 & .035 & -.162 & -.017 \\
\hline $\begin{array}{l}\text { Frequency of } \\
\text { Contacts }\end{array}$ & .031 & .004 & .212 & .040 & .568 & .069 \\
\hline $\begin{array}{l}\text { Citizen-Initiated } \\
\text { Contacts }\end{array}$ & $2.148 * * *$ & .122 & -.789 & -.068 & -.033 & -.002 \\
\hline $\begin{array}{l}\text { Police-Initiated } \\
\text { Contacts }\end{array}$ & .140 & .007 & -.507 & -.039 & .288 & .015 \\
\hline Exposure to Media & .516 & .054 & $.552 *$ & .087 & $.828^{*}$ & .085 \\
\hline Victimization & -.144 & -.007 & -.940 & -.070 & -1.888 & -.091 \\
\hline $\begin{array}{l}\text { Victim of Property } \\
\text { Crimes }\end{array}$ & 1.127 & .064 & .501 & .043 & 1.483 & .083 \\
\hline $\begin{array}{l}\text { Victim of Crimes A/ } \\
\text { Persons }\end{array}$ & -.238 & -.013 & .871 & .074 & 1.741 & .095 \\
\hline $\begin{array}{l}\text { Fear of Criminal } \\
\text { Retaliation }\end{array}$ & $-1.084 * * *$ & -.156 & -.274 & -.060 & $-1.163^{* * *}$ & -.163 \\
\hline $\begin{array}{l}\text { Crime-reporting } \\
\text { Anonymity }\end{array}$ & .036 & .015 & .076 & .049 & $.267^{*}$ & .111 \\
\hline Police Behavior & -.014 & -.028 & -.014 & -.045 & $-.099 * * *$ & -.202 \\
\hline \multirow[t]{4}{*}{$\begin{array}{l}\text { Attitudes toward the } \\
\text { Police }\end{array}$} & $.147 * * *$ & .382 & $.039 * * *$ & .154 & .041 & .105 \\
\hline & \multicolumn{2}{|l|}{ Model 1} & \multicolumn{2}{|l|}{ Model 2} & \multicolumn{2}{|l|}{ Model 3} \\
\hline & \multicolumn{2}{|l|}{$\mathrm{R} 2=.287$} & \multicolumn{2}{|l|}{$\mathrm{R} 2=.114$} & \multicolumn{2}{|l|}{$\mathrm{R} 2=.223$} \\
\hline & \multicolumn{2}{|c|}{$\mathrm{F}(17,513)=12.128 * * *$} & \multicolumn{2}{|c|}{$\mathrm{F}(17,513)=3.894 * * *$} & \multicolumn{2}{|c|}{$\mathrm{F}(17,513)=8.646^{* * *}$} \\
\hline
\end{tabular}

Note: ***Significance at the .001 level. ** Significance at the .01 level. * Significance at the .05 level. Dependent Variables: Crime-Reporting 1 (reporting of less serious crimes), crime-reporting 2 (reporting of medium-level crimes), crime-reporting 3 (reporting of serious crimes). SES= Socio-Economic Status.

Table 4. Hierarchical Regression Analysis: Regressing Crime-Reporting 1 on Prior Victimization (for Crimes Against Persons) $(n=531)$ 


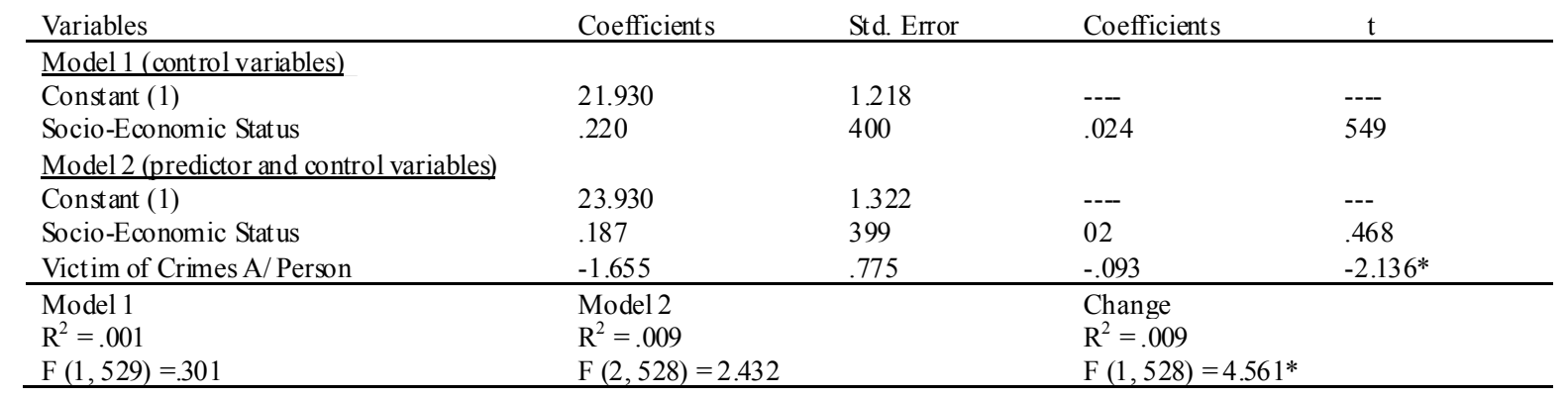

Note: ***Significance at the .001 level. $* *$ Significance at the .01 level. ${ }^{*}$ Significance at the .05 level. Dependent Variables:

Constant $(1)=$ Crime-reporting 1 (scale for measuring the reporting of less serious crimes).

Table 5. Hierarchical Regression Analysis: Regressing Crime-Reporting 2 on Prior Victimization (for Crimes Against Persons) $(n=531$ )

\begin{tabular}{|c|c|c|c|c|}
\hline Independent & Unstandardized & & Standardized & \\
\hline Variables & Coefficients & Std. Error & Coefficients & $\mathrm{t}$ \\
\hline \multicolumn{5}{|l|}{ Model 1 (control variables) } \\
\hline Const ant (2) & 21.774 & .804 & --- & --- \\
\hline Socio-Economic Status & .162 & .264 & .02 & .615 \\
\hline \multicolumn{5}{|c|}{ Model 2 (predictor and control variables) } \\
\hline Const ant (2) & 21.926 & 877 & --- & --- \\
\hline Socio-Economic Status & .158 & .265 & .026 & .597 \\
\hline Victim of Crimes A/ Person & -.224 & .514 & -.019 & -.019 \\
\hline $\begin{array}{l}\text { Mode } 1 \\
\mathrm{R}^{2}=.00111\end{array}$ & $\begin{array}{l}\text { Model } 2 \\
\mathrm{R}^{2}=.001\end{array}$ & & $\begin{array}{l}\text { Change } \\
\mathrm{R}^{2}=.000\end{array}$ & \\
\hline $\mathrm{F}(1,529)=.378$ & $\mathrm{~F}(2,528)=.284$ & & $\mathrm{~F}(1,528)=$. & \\
\hline
\end{tabular}

Note: ***Significance at the .001 level. **Significance at the .01 level. *Significance at the .05 level. Dependent Variables:

Constant (2) = Crime-reporting 2 (scale for measuring the reporting of medium-level crimes).

Table 6. Hierarchical Regression Analysis: Regressing Crime-Reporting 3 on Prior Victimization (for Crimes Against Persons) $(n=531)$

\begin{tabular}{|c|c|c|c|c|}
\hline Independent & Unstandardized & & Standardized & \\
\hline Variables & Coefficients & Std. Error & Coefficients & $\mathrm{t}$ \\
\hline \multicolumn{5}{|c|}{ Model 1 (control variables) } \\
\hline Constant (3) & 42.650 & 1.243 & --- & ---- \\
\hline Socio-Economic Status & .185 & .408 & .020 & .454 \\
\hline \multicolumn{5}{|c|}{ Model 2 (predictor and control variables) } \\
\hline Constant (3) & 42.843 & 1.355 & --- & ---- \\
\hline Socio-Economic Status & .180 & .409 & .019 & .439 \\
\hline $\begin{array}{l}\text { Victim of Crimes A/ } \\
\text { Person }\end{array}$ & -.285 & .794 & -.016 & -.359 \\
\hline $\begin{array}{l}\text { Model } 1 \\
\mathrm{R}^{2}=.000\end{array}$ & $\begin{array}{l}\text { Model } 2 \\
\mathrm{R}^{2}=.001\end{array}$ & & $\begin{array}{l}\text { Change } \\
\mathrm{R}^{2}=.000\end{array}$ & \\
\hline $\mathrm{F}(1,529)=.206$ & $F(2,528)=.167$ & & $\mathrm{~F}(1,528)=.129$ & \\
\hline
\end{tabular}

Note: ***Significance at the .001 level. **Significance at the .01 level. *Significance at the .05 level. Dependent Variables: Constant $(3)=$ Crime-reporting 3 (scale for measuring the reporting of serious crimes).

Hypothesis 3 predicted that when controlling for socio-economic status, individuals who have been victims of crimes against persons are less likely to report victimization events or witnessed crimes to the police compared to individuals who have not been victims of crimes against persons. To test hypothesis 3 , we used hierarchical regression analysis. Since we were concerned that socio-economic status might be related to both prior victimization and crime-reporting behavior, it seemed more appropriate to place statistical controls for this effect. Thus, the effect of prior victimization on crime-reporting behavior is independent of the effect of SES.

The socio-economic status was entered in step 1 (or Model 1 ), explaining only $0.1 \%$ of the variation in the reporting of less serious crimes, $0.1 \%$ in the reporting of medium-level crimes, and $0 \%$ in the reporting of serious crimes. Prior victimization was entered in step 2 (or Model 2). After controlling for the influence of socio-economic status, the $\mathrm{R}^{2}$ change for crime-reporting 1 was $.009, F$ change $(1,528)=$ $4.561, \mathrm{p}<.05$. This means that prior victimization accounted for appro ximately $1 \%$ of the variation on the report ing of less serious crimes (crime-reporting 1, see Table 4). For the reporting of med ium-level crimes (crime-reporting 2), the $\mathrm{R}^{2}$ change was $.000, \mathrm{~F}$ change $(1,528)=.191, \mathrm{p}<.663$ (Table 5). And for the reporting of serious crimes (crime-reporting 3), the $\mathrm{R}^{2}$ change was $.000, \mathrm{~F}$ change $(1,528)=.129, \mathrm{p}<.720$ (see Table 6). This means that the influence of prior victimization is greater for the reporting of less serious crimes (explaining $1 \%$ of the variation), but this influence tends to decrease as the seriousness of crime increased, 
explaining approximately $0 \%$ of the variation in the reporting of medium-level crimes and $0 \%$ of the variation in the reporting of serious crimes.

In terms of the direction of the influence of prior victimization on crime-reporting behavior, the analyses in Tables 4, 5, and 6 show that prior victimization has a negative effect on crime-reporting behavior $(b=-1.655$ for less serious crimes, $b=-.224$ for medium-level crimes, and $b$ $=-.285$ for serious crimes). This means that people who have previously been victims of crimes against persons are less likely to report crimes to the police. Conversely, people who have not previously been victims of crimes against persons are more likely to report crimes to the police. However, the effects of prior victimization (for victims of crimes against persons) on crime-reporting behavior reached statistical significance of $\mathrm{p}<.05$ only for the reporting of less serious crimes. On the other hand, being a victim of crimes against persons did not have a statistically significant effect on the reporting of medium-level crimes and serious crimes. Therefore, hypothesis 3 is rejected.

\section{Discussion and Conclusions}

The effect of prior victimization on crime-reporting behavior largely depends on intervening variables. That is, prior victimization by itself is not a strong determinant of crime-reporting behavior. Some researchers suggest that crime-reporting behavior is affected by the victim's prior experience with the police, by whether or not an arrest is made by the police in an effort to investigate the crime that has affected the victim, and by the police response to the individual's own prior victimization rather than victimization of another hous ehold member[see 8,12]. This tells us that the victim's decision whether or not to report crimes or victimization events to the police is, to some degree, affected by external factors (e.g., police behavior), factors other than victimization events. However, external factors such as police behavior may have positive or negative effects only on the victim's motivation to report crimes to the police. Needless to say, motivation is not the only necessary element that determines one's crime-reporting behavior. Sometimes, victims of crime are forced to put a stop to, for instance, repeat victimizations[43]. This means that, regardless of the negative effects of external factors (e.g., police behavior, fear of criminal retaliation, etc), the decision to report crimes to the police can be affected purely by the victim's perception of the event, which in most cases includes taking into account the seriousness of the victimization events, the type of victimization events (i.e., being a vict im of p roperty crimes vs. being a victim of crimes against persons), and the relationship between the victim and the offender[see 5,11,22,34,45,53,64-66, for reviews].

The current study is limited to examining whether or not prior victimization is a strong predictor of crime-reporting behavior. To address this issue, three research hypotheses were developed and tested in this study. Hypothesis one predicted that individuals who have been previously victimized by crime - regard less of the type of crime (e.g., property crimes or crimes against persons ) - are more likely to report witnessed crimes or victimization events to the police. The findings of this study suggest that being victimized by a crime had an insignificant effect on crime-reporting behavior. In other words, the data in the current study suggest that the decision whether or not to report a crime to the police is not affected by prior victimization status.

To further examine the effect of prior victimization, this time by the type of victimization events (i.e., by looking at the difference between victims of property crimes and those who never been victims of property crimes), another research hypothesis was tested. In this context, hypothes is two predicted that individuals who have been victims of property crimes are mo re likely to report crimes to the police. The results of the current study show that being a victim of property crime had an insignificant effect on crime-reporting behavior. By the severity of crimes, this effect was statistically insignificant for all three levels of reporting (i.e., the reporting of less serious crimes, medium-level crimes, and serious crimes). Additionally, the effect of victimization for property crime on crime-reporting behavior did not reach the statistical significance of $p<.05$ at the multivariate level either. In terms of the positive or negative direction of the effect, the research findings of the current study suggest that victims of property crimes are generally more likely to report less serious crimes and serious crimes, but less likely to report medium-level crimes.

The last research hypothes is tested in this study predicted that individuals who have been victims of crimes against persons are less likely to report witnessed crimes or victimization events to the police compared to those who have not been victims of such criminal events. At the bivariate level of the analysis, the research results of the current study somewhat support this hypothesis. Although the effect was insignificant, the current study suggests that individuals who have been victims of crimes against persons are less likely to report crimes to the police. Unexpectedly, this finding changed when tested at the multivariate level. Thus, the multivariate analyses show that being a victim of crimes against persons has a positive effect on crime-reporting behavior.

In summation, this study is limited to addressing the effect of prior victimization on crime-reporting behavior by 1) the type of victimization (i.e., being a victim of property crimes or a victim of crimes against persons),2) being a victim of a crime, regardless of the type of crime versus not being a victim, and 3) the difference in crime-reporting variation between the two. Overall, the findings of the current study suggest that prior victimization cannot be considered a good predictor of crime-reporting behavior. Although, an attempt has been made to clarify contradicting results in previous studies, more research is needed in this area. In this study, for example, we did not examine the relationship between the victim and the offender. Prior literature suggests that the 
victim-offender relationship is one of the major factors that affect a victim's crime-reporting behavior. Along this line, there are a number of studies showing that an increased social distance between the victim and the offender results in an increased reporting of witnessed crimes and victimization events to the police[35,42,45,67-69, see also 30,70]. Bach man, for example, found that victims of rape were mo re likely to report victimization events to the police when the perpetrator was unknown to them[45,46,68]. In this context, research shows that most sexual as saults, including rape, are committed by someone known to the victim[7-73]. This tells us that a great number of vio lent crimes (e.g., rape and sexual assault) go unreported, which can be attributed to the victim-offender relationship. Future research should fill this gap by exploring the effect of victim-o ffender relationship on crime-reporting behavior. Additionally, the seriousness of crime has also been identified as a key factor that affects crime-reporting behavior. Thus, future research should examine whether or not there is a strong association between the seriousness of the offense and the victim-offender relationship, and to what extent these two factors affect crime-reporting behavior. Future research should also examine the difference in the reporting of violence committed by strangers and violence committed by less intimate known offenders (e.g. coworkers, friends, and relatives).

\section{Appendix A}

In the Appendix A, we have included the items that we used to measure willingness to report crime to the police. In this study, we referred to this construct as "crime-reporting behavior." The respondents were asked: Would you report to the police or school officials if:

1. You saw someone smoking in the school bathroom?

2. You saw someone using illicit drugs in the school bathroom?

3. You saw someone selling ecstasy in the school bathroom?

4. You saw someone you know selling cocaine in the school bathroom?

5. You saw someone selling cocaine in the school bathroom and they saw you?

6. You saw someone illegally dumping oil on the ground/sewage system (polluting the environment)?

7. You saw someone painting graffiti on the walls of a public/or private building?

8. You saw a male student, whom you do not know, physically as saulting a female student in the school parking?

9. You saw a male student smashing the windshield of a car in the parking lot.

10. You saw someone attempting to commit a burglary (illegal entry or attempt breaking and entering into someone's property/house)?

11. You heard someone making a physical threat (verbally) to someone you do not know?
12. You saw your friend yell at his girlfriend and heard her yell back that he is trying to kill her.

13. You saw your friend yell at his girlfriend, heard her yell back that he is trying to kill her and saw him brandish a knife.

14. You saw a student, whom you do not know, yell at a female, you heard her yell back that he is trying to kill her and saw him brandish a knife.

15. You saw a male driver stopped his car and grabbed a female forcing her into his car and then he drove away with the girl. You heard the girl screaming and trying to fight back.

16. You heard a girl, whom you do not know, screaming behind the bleachers of the football field that someone is trying to rape her.

17. You saw a man in the school cafeteria attempting to rob the place.

18. You heard a girl you know screaming behind the bleachers of the football field that someone is trying to rape her.

19. You heard from a trusted source that a girl was raped after the football game?

20. You found a journal entry from a college student that described making a bo mb?

21. You overheard some college students bragging about knowing how to make a bomb?

22. You saw some college students hiding something inside of their large overcoats and acting suspiciously

23. A student, whom you know, told you he is going to make a bo mb

24. So meone you know has told you he has killed a person and has taken you to the place where he has dumped the body, and you see the dead body.

\section{REFERENCES}

[1] Skogan, W. G. (1976). Crime and crime rates. In W. G. Skogan (Ed.), Sample surveys of the victims of crime (pp. 105-120). Cambridge, MA: Ballinger Publishing Co.

[2] Skogan, W. G. (1984). Reporting crime to the police: The status of world research. Journal of Research in Crime and Delinquency, 21 (2), 113-137.

[3] Goudriaan, H. (2006). Reporting crime: Effects of social context on the decision of victims to notify the police. Veenendaal: University press.

[4] Greensburgh, M. S., Wilson, C. E., \& Ruback, B. R. (1979). Social and emotional determin ants of victim crime reporting. Social Psychology Quarterly, 42 (4), 364-372.

[5] Conaway, M. R., \& Lohr, S. L. (1994). A longitudinal analy sis of factors associated with reporting violent crimes to the police. Journal of Quantitative Criminology, 10, 23-39.

[6] Meadows, R. J. (1998). Understanding violence and victimization. Upper Saddle River, NJ: Prentice Hall.

[7] Watkins, A. M. (2005). Examining the Disparity between Juvenile and Adult Victims in Notifying the Police: A Study 
of Mediating Variables. Journal of Research in Crime and Delinquency, 42 (3), 333-353.

[8] Xie, M., Panarsky, G., Lynch, J. P., \& McDowall, D. (2006). Prior police contact and subsequent victim reporting: Results for the NCVS. Justice Quarterly, 23 (4) 481-501.

[9] Doener, W. G., \& Steven L. P. (2011). Victimology (6th ed.). Cincinnati, OH: Anderson Publishing, Inc.

[10] Tanton, R., \& Jones, R. (2003, March). Australian victims' propensity to report assault and break and enter to police. Paper Presented at the Evaluation in Crime and Justice: Trends and Methods Conference, Canberra, Australia.

[11] Zhang, L., Messner, S. F., \& Liu, J. (2007). An exploration of the determinants of reporting crime to the police in the city of Tianjin, China. Criminology, 45 (4), 959-981.

[12] Hickman, L. J., \& Simpson, S. S. (2003). Fear treatment of preference outcome? The impact of police behavior on victim reports of domestic violence incidents. Law \& Society Review, 37 (3), 607-634.

[13] Holmberg, U. (2004). Crime victims' experiences of police interview and their inclination to provide or omit information. International Journal of Police Science \& Management, 6 (3), 155-170.

[14] Unnever, J. D., \& Cornell, D. G. (2004). Middle school victims of bully ing: who reports being bullied? Aggressive Behavior, 30 (5), 373-388.

[15] Tilley, N. (2005). Handbook of crime prevention and community safety. Devon, UK: Willan Publishing.

[16] Williams, F., \& Cornell, D. (2006). Student willingness to seek help for threats of violence. Journal of School Violence, $5,35-49$.

[17] Smith, D. A. (1986). The neighborhood context of police behavior. Crime and Justice, 8, 313-341.

[18] Goudriaan, H., Wittebrood, K., \& Nieuwbeerta, P. (2006). Neighborhood characteristics and reporting crime: Effects of social cohesion, confidence in police effectiveness and socio-economic disadvantage. British Journal of Criminology, $46,719-742$.

[19] Baumer, E. P. (2002). Neighborhood disadvantage and police notification by victims of violence. Criminology, 40, 579-616.

[20] Fishman, G. (1979). Patterns of victimization and notification. British Journal of Criminology, 19, 146-157.

[21] Tankebe, P. J. (2009). Public cooperation with the police in Ghana: Does procedural fairness matter? Criminology, 47 (4), $1265-1294$

[22] Carcach, C. (1997). Reporting crime to the police. Australia: Australian Institute of Criminology

[23] Fisher, B. S., Daigle, L. E., Cullen, F. T., \& Turner, M. G. (2003). Reporting sexual victimization to the police and others: Results from a national-level study of college women. Criminal Justice and Behavior, 30 (1), 6-38.

[24] Johnson, T. R. (1993). The public and the police in the city of Chicago. Chicago, IL: Northwestern University.

[25] Kane, R. J. (2002). The social ecology of police misconduct. Criminology, 40, 867-896.
[26] Kubrin, C. E., \& Weitzer, R. (2003). New directions in social disorganization theory. Journal of Research in Crime and Delinquency, 40 (4), 374-402.

[27] Rice, K. J., \& Smith, W. R. (2002). Socioeconomic models of automotive theft: Integrating routine activity and social disorganization ap proaches. Journal of Research in Crime and Delinquency, 39, 304--336.

[28] Jensen, G. F. (2003). Social disorganization theory. In Wright, R. A. (Ed.), Encyclopedia of Criminology, New York, NY: Fitzroy Dearborn Publishers.

[29] Kelly, M. (2000). Inequality and crime. The Review of Economics and Statistics, 82 (4), 530-539.

[30] Skogan, W. G. (1976). Citizen Reporting of crime: Some national panel data. Criminology, 13 (4), 535-551.

[31] Bureau of Justice Statistics. (2005). Hate crimes reporting by victims and police. Washington, DC: U.S. Department of Justice.

[32] Liska, A. E. (1992). Social threat and social control. Albany, NY: State University of New York Press.

[33] Bureau of Justice Statistics. (2006). Characteristics of drivers stopped by police, 2002. Washington, DC: U.S. Department of Justice.

[34] Skogan, W. G. (1984). Reporting crime to the police: The status of world research. Journal of Research in Crime and Delinquency, 21 (2), 113-137.

[35] Bureau of Justice Statistics. (2003). Reporting crime to the police, 1992-2000. Washington, DC: U.S. Department of Justice.

[36] Bennett, R. R., \& Wiegand, B. R. (1994). Observations on crime reporting in a developed nation. Criminology, 32 (1), 135-148.

[37] Gottfredson, M. R, Gottfredson, D. M. (1987). Decision Making in Criminal Justice: Toward the Rational Exercise of Discretion. New York: Springer-Verlag New York, LLC.

[38] Snyder, H. N. (2000). Sexual assault of young children as reported to law enforcement: Victim, incidents, and offender characteristics. Washington, D. C: Department of Justice.

[39] Durose, M. R., Harlow, C. W., Langan, P. A., Motivans, M., Rantala, R. R., \& Smith, E. L. (2005). Family violence statistics: Including statistics on strangers and acquaintances. Washington, D. C: Department of Justice.

[40] Greensburg, M. S., \& Ruback, B. R. (1992). After the crime: Victim decision making. New York: Plenum.

[41] Block, J., \& Block, J. H. (1980). The California child q-set. Palo Alto, CA: Consulting Psychologists Press.

[42] Gartner, R., \& Macmillan, R. (1995). The effect of victim-offender relationship on reporting crimes of violence against women. Canadian Journal of Criminology, 27, 393-429.

[43] Watkins, A. M. (2005). Examining the Disparity between Juvenile and Adult Victims in Notifying the Police: A Study of Mediating Variables. Journal of Research in Crime and Delinquency, 42 (3), 333-353.

[44] Block, R. (1974). Why notify the police: The victim's 
decision to notify the police of an assault. Criminology, 11 (4), 555-569.

[45] Bachman, R. (1993). Predicting the reporting of rape victimizations: Have rape reforms made a difference? Criminal Justice and Behavior, 20 (3), 254-270.

[46] Bachman, R. (1998). The factors related to rape reporting behavior and arrest: New evidence from the national crime victimization survey. Criminal Justice and Behavior, 25 (1), 8-29.

[47] Hickman, L. J., \& Simpson, S. S. (2003). Fear treatment of preference outcome? The impact of police behavior on victim reports of domestic violence incidents. Law \& Society Review, 37 (3), 607-634.

[48] Holmberg, U. (2004). Crime victims' experiences of police interview and their inclination to provide or omit information. International Journal of Police Science \& Management, 6 (3), 155-170.

[49] Bureau of Justice Statistics. (2005). Violent victimization of college students, 1995-2002. Washington, DC: U.S. Department of Justice.

[50] Kaiser, H. F. (1974). An index of factorial simplicity. Psy chometrika, 39, 31-39.

[51] Marjorie, P. A., Lackey, N. R., \& Sullivan, J. J. (2003). Making sense of factor analysis: The use of factor analy sis for instrument development in health care research. Thousand Oaks, CA: Sage Publication, Inc.

[52] Meyers, L. S., Gams, G. C., \& Guarino, A. J. (2005). Applied multivariate research: Design and interpretation. Thousand Oaks, CA: Sage Publication, Inc.

[53] Bartlett, M. S. (1954). A note on the multiplying factors for various chi square approximations. Journal of the Royal Statistical Society, 16, 296-298.

[54] Child, D. (2006). The essentials of factor analysis (3rd ed). New York: Continuum International Publishing Group.

[55] Tobias, S., \& Carlson J. (1969). Bartlett's test of sphericity and chance findings in factor analysis. Multivariate Behavioral Research, 4, 375-378.

[56] Weitzer, R., \& Tuch, S. A. (1999). Race, class, and perceptions of discrimination by the police. Crime \& Delinquency, 45 (4), 494-507.

[57] Weitzer, R., \& Tuch, S. A., (2005). Determinants of public satisfaction with the police. Police Quarterly, 8 (3), 279-297.

[58] Crowne, D. P., \& Marlowe, D. (1960). A new scale of social desirability independent of psychopathology. Journal of Consulting Psychology, 24, 349-354

[59] McCrae, R. R., \& Costa, P. T. (1983). Social desirability scales: More substance than style. Journal of Consulting and Clinical Psychology, 51 (6), 882-888.

[60] Ray, J. J. (1984). The reliability of short social desirability scales. The Journal of So cial Psychology, 123, 133-134.

[61] Zerbe, W. J., \& Paulhus, D. L. (1987). Socially desirable responding in organizational behavior: A reconception. Academy of Management Journal, 12 (2), 250-264.

[62] DeVellis, R. F. (2003). Scale development: Theory and applications (2nd ed.). Thousand Oaks, CA: Sage Publications, Inc.

[63] Moorman, R. H., \& Podsakoff, P.M. (1992). A meta-analy tic review and empirical test of the potential confounding effects of social desirability response sets in organizational behavior research. Journal of Occupational and Organizational Psychology, 65, 131-149.

[64] Goudriaan, H., \& Nieuwbeerta, P. (2007). Contextual determinants of juveniles' willingness to report crime: A vignette exp eriment. Journal of Experimental Criminology, 3, 89-111.

[65] Finkelhor, D., \& Wolak, J. (2003). Reporting assaults against juveniles to the police: Barriers and catalysts. Journal of Interpersonal Violence, 18 (2), 103-128.

[66] Finkelhor, D., Wolak, J. \& Berliner, L. (2001). Police reporting and professional help seeking for child crime victims: A review. Child Maltreatment, 6 (1), 17-30.

[67] Kaukinen, C. (2002). The help-seeking decisions of violent crime victims: An examination of the direct and conditional effects of gender and the victim-offender relationship. Journal of Interpersonal violence, 17 (4), 432-456.

[68] Williams, L. S. (1984). The classic rape: When do victims rep ort? Social Problems, 31, 459-467.

[69] Bureau of Justice Statistics. (2002). Rape and sexual assault: Reporting to police and medial attention, 1992-2000. Washington, DC: U.S. Department of Justice.

[70] Pescosolido, B. (1992). Beyond rational choice: The social dynamics of how people seek help. American Journal of Sociology, 97 (4), 1096-1138.

[71] Bureau of Justice Statistics. (1997). A ge patterns of victims of serious violent crimes. Washington, DC: U.S. Department of Justice.

[72] Bureau of Justice Statistics. (1997). Sex offenses and offenders: An analysis of data on rape and sexual assault. Washington, DC: U.S. Department of Justice.

[73] Bureau of Justice Statistics. (2005). Crimes against persons age 65 or older, 1993-2002. Washington, DC: U.S. Department of Justice. 